\title{
In Vitro, in Vivo and in Field Sensitivity of Venturia inaequalis to Anilinopyrimidine Fungicides with Different Types of Scab Management and Degree of Control
}

\author{
Riccardo Fiaccadori \\ Department of Agricultural and Food Sciences (DISTAL), University of Bologna, Bologna, Italy \\ Email: riccardo.fia ccadori@unibo.it
}

How to cite this paper: Fiaccadori, R. (2018) In Vitro, in Vivo and in Field Sensitivity of Venturia inaequalis to Anilinopyrimidine Fungicides with Different Types of Scab Management and Degree of Control. Open Access Library Journal, 5: e5092.

https://doi.org/10.4236/oalib.1105092

Received: December 4, 2018

Accepted: December 24, 2018

Published: December 27, 2018

Copyright (c) 2018 by author and Open Access Library Inc.

This work is licensed under the Creative Commons Attribution International License (CC BY 4.0).

http://creativecommons.org/licenses/by/4.0/

\section{(c) (i) Open Access}

\begin{abstract}
The sensitivity of Venturia inaequalis to anilino-pyrimidine (AP) fungicides (pyrimethanil and cyprodinil) was studied on populations sampled from apple trees with different fungicide and APs histories: 1) apple trees in uncultivated areas never exposed to fungicides (wild types), 2) commercial orchards with many years of good scab control with APs (well-controlled); 3) populations in experimental Centre where an initial good activity decreased after several years of intensive use (poorly controlled). The in vitro sensitivity tests were performed on monoconidial isolates, while those in vivo with curative or preventive applications on populations inoculated on apple seedlings. In the field, the infection on apple trees was assessed as severity of attack on leaves. The results evidenced that the sensitivity in vitro to pyrimethanil and cyprodinil showed a progressive lower reduction from wild types to well controlled, ending with poorly controlled populations. In vivo tests the same moderate decrease of sensitivity and activity (with a wide range) was more evident with curative, respect preventive applications, as noticed also with an important DMI (difenoconazole). In field trials, the populations intensively treated with APs showed, after some years, a reduction of control, that was confirmed in the following years. These activity reductions were sensibly less strong respect those evidenced by strobilurins, both in field and in vitro tests. The particular characteristic of resistance to AP fungicides is discussed.
\end{abstract}

\section{Subject Areas}

Agricultural Science 


\section{Keywords}

Venturia inaequalis, Apple Scab Control, Sensitivity, Resistance, AP Fungicides, Pyrimethanil, Cyprodinil

\section{Introduction}

The presentation of anilino-pyrimidine fungicides (AP, mepanipyrim, pyrimethanil, and cyprodinil) was in the early 1990's [1] [2]. These fungicides were successfully introduced worldwide for the control of several diseases, especially grey mould (Botrytis cinerea) on grapevine and strawberries, apple scab (Venturia inaequalis) and brown rot (Monilia spp.) of Drupacee fruits; cyprodinil was developed also for the control of some cereal diseases [3].

Concerning $V$. inaequalis, the ability of anilinopyrimidines pyrimethanil and cyprodinil to exert post-infection activity even at low temperatures favoured their success, mostly in the first vegetative phases.

In every case, their employ was extended from "tip mouse" stage until the "end of bloom", because the protection of fruits appeared to be less satisfactory [4]. The practical application of AP fungicides was also favoured by the presence of resistance to DMI in Venturia inaequalis.

There are also studies regarding the sensitivity/resistance of fungi to AP fungicides: Botrytis cinerea is the most studied phytopathogen fungus about resistance to AP fungicides, and in vitro researches, realized on satisfactory treated [5] and on untreated populations [6], showed the presence of spores with very different "Resistant Factors" (RF, from 2 - 3 up to 100 and also 1000-fold), but in a low frequency. On the contrary, the few accepted cases of field resistance, mostly on Botritis spp., showed that resistant spores had a frequency from 37 to 57\% [7] [8], but with an unknown RF.

There are few reports describing the sensitivity of $V$. inaequalis to APs: Schnabel and Parisi [9], Kunz [10], Koller [11] that analized samples from field and described normal sensitivity in vitro and in vivo assays.

The in vitro tests on $V$. inaequalis of the previous Authors had the characteristics to use an agar poor in sugars and amino acids, especially methionine and cysteine. The reason is that the target of AP fungicides seems mainly based on inhibition of synthesis of these amino acids [12] and their abundant presence in agar could counteract the activity of these fungicides and misunderstanding the sensitivity of fungi.

In addition, to avoid misleading evaluations of in vitro results, there is the advice to integrate in vitro tests with in vivo ones, as was pointed out by some Authors [6] [9].

In vivo tests were utilized for a monitoring in Europe on sensitivity to cyprodinil in orchards by Dux [13], classifying $V$. inaequalis populations in sensitive and resistant. 
Situations of declared control failures are limited and are represented by a case of reduced control in an orchard intensively treated with cyprodinil in Italy [14].

There is also a report of control complains in commercial orchards from France [15], but sensitivity data are not presented. There is moreover a particular situation, observed in the U.S.A., in an orchard with resistance to DMI, and where cross-resistance with pyrimethanil caused a similar problem [11].

A preliminary survey on sensitivity, especially referred to pyrimethanil, was carried out in Northern Italy in an experimental orchard with intensive applications of this fungicide, showing a reduced control [16].

In this paper, we present an extension of this first research, with a further and more complete study, in vitro, in vivo and in the field, about the sensitivity of the three different types of $V$. inaequalis populations and monoconidial isolates on pyrimethanil and cyprodinil.

\section{Materials and Methods}

\subsection{Origin of the Types of $V$. inaequalis Populations}

Populations of $V$. inaequalis were sampled in Northern Italy from apple trees located in three different situations concerning apple scab management:

- Apple trees never treated with fungicides, located in an uncultivated area (a wild type population collected in 2002);

- Commercial orchards where pyrimethanil or cyprodinil have been applied for many years in control programs with satisfactory results (four "well controlled" populations in orchards sampled in 2004);

- Experimental orchard, where pyrimethanil and cyprodinil have been intensively applied in plot trials. The intensive use began in 1995 for pyrimethanil and in 1997 for cyprodinil. A reduced control has been observed since 2004 for pyrimethanil and since 2005 for cyprodinil. In the same trial orchard, strobilurins were also applied (with the same intensive schedule), and resistance was detected from 2003 for kresoxim-methyl and trifloxystrobin.

The samples examined in laboratory and greenhouse consisted of $30-40$ scabbed leaves from field, collected and chosen in accordance with monitoring standards [17], where conidia where utilized in a different way considering in vitro and in vivo tests.

The first presented methodology is that in vitro, as it was the most advised and diffused to assay sensitivity.

\subsubsection{In Vitro: Preparation}

These trials concerned the activity of pyrimethanil and cyprodinil on monoconidial colonies of $V$. inaequalis in Petri plates on the medium "Agar Grade A" (2\%, DIFCO, Detroit, USA) + Malt extract (2.5\%, DIFCO) This substrate did not contain amino acids, as recommended by Masner [12] and was used at low content of sugars (maltose, $12 \mathrm{~g} / \mathrm{L}$ ). It was preliminarily compared with asp-agar of Hilber and Schüepp [18], the most commonly used substrate in assays with APs, 
which presents a higher sugar content $(22 \mathrm{~g} / \mathrm{l})$. We carried out preliminary tests with these two agars and activity of AP fungicides on mycelium growth was similar on the two media, so "Agar Grade A" and Malt extract was chosen for tests (unpublished data).

Pyrimethanil and cyprodinil were dissolved in acetone (final concentration $<1 \% \mathrm{v} / \mathrm{v}$ ) and added to the medium to achieve the following concentrations: 0 , $0.001,0.01,0.1,1,10,50 \mathrm{mg} / \mathrm{L}$. Streptomycin sulphate (Sigma-Aldrich, St. Louis, USA).was added to the liquid agar to give the final concentration of $200 \mathrm{mg} / \mathrm{L}$.

\subsubsection{In vitro: Tests on Monoconidial Colonies}

From each population of the three different types, one or two scab spots/leaf for 30 leaves were marked and a drop of $20 \mu \mathrm{L}$ of sterile water was put on each spot. The drops were sucked up with a Pasteur pipette and put in micro tubes.

The conidia dispersion was then placed on a Petri dish with "Agar grade A" (2.2\%, DIFCO) amended with streptomycin sulphate $300 \mathrm{mg} / \mathrm{l}$. Twenty-four hours later the germinated conidia (30 - 40 for each population) were picked up using a stereomicroscope (70× magnification), and put individually in a Petri dish with PDA (3.9\%, DIFCO) where they were grown for about 60 days and then used for tests.

\subsection{Fungicides}

In vitro tests, technical materials of the two fungicides pyrimethanil and cyprodinil were utilized (Sigma-Aldrich, St. Louis, USA).

\subsubsection{In Vivo: Moltiplication of Field Populations}

The populations of field samples were multiplied on apple seedlings in glasshouse. A drop of sterile water was added on each of 30 - 40 scab spots per sample and then aspirated with a Pasteur pipette. The conidial suspension was inoculated, placing 20 - $30 \mu \mathrm{l}$ drops on leaves of apple seedlings. After the sporulation of the fungus, scabbed leaves were collected and maintained in plastic bag with silica gel at $5^{\circ} \mathrm{C}$ until the beginning of the tests.

The bulk populations were utilized for the sensitivity tests in vivo on apple seedlings.

\subsubsection{In Vivo: Tests}

The tests were carried out on cv. Golden Delicious apple seedlings at the stage of 5 - 6 leaves. The seedlings, obtained from vernalisation of Golden seeds, were grown in glasshouse on substrate containing turf (60\%), sand (10\%) and perlite (30\%), for $20-25$ days with a temperature of $18^{\circ} \mathrm{C}-22^{\circ} \mathrm{C}$ and 14 hours photoperiod.

Inoculation of $V$. inaequalis populations was performed in glasshouse with a suspension of conidia at the concentration of $1-2 \times 10^{5} \mathrm{spore} / \mathrm{ml}$ of sterile water that was uniformly sprayed on both leaf surfaces $(1.2 \mathrm{ml} /$ plant $)$. The seedlings were then put in a plastic closed container, to maintain wetness on leaves for 48 hours at $18^{\circ} \mathrm{C}$. Subsequently the plants were incubated for a further 18 days with 
light at an intensity of $25 \mu$ Einstein $\mathrm{m}^{-2} \cdot \mathrm{s}^{-2}$ and a photoperiod of 12 hours a day, temperature $18^{\circ} \mathrm{C}-21^{\circ} \mathrm{C}$ and $60 \%-80 \%$ relative humidity.

The application of fungicides pyrimethanil and cyprodinil (see 2.2.3) was carried out before ( 1 or 3 days) or after ( 2 days) the moment of inoculation, spraying cited fungicides. The assessment of $V$. inaequalis infection was performed as degree of attack by Mc Kinney, 20 days after inoculation, on the last 3 formed leaves present at the time of treatment (tagged with a plastic string). Data were transformed in relative efficacy (percentage) and, for each treatment, 6 - 7 plants were initially assayed, subsequently reduced to five. Two or three assays were carried out for each population and treatment. All bulk populations sampled in the three different field situations were analysed both in preventive and curative tests.

\subsection{Fungicides}

Commercial formulations of pyrimethanil (SCALA, BASF) and cyprodinil (CHORUS, Syngenta) were used at field rates: $0.8 \mathrm{~g} / \mathrm{L}$ (37\% a.m. corresponding to $0.3 \mathrm{~g} / \mathrm{L}$ ) for pyrimethanil and $0.5 \mathrm{~g} / \mathrm{L}(50 \%$ a.m. corresponding to $0.25 \mathrm{~g} / \mathrm{L}$ ) for cyprodinil, distributing about $2.5 \mathrm{~mL} /$ plant with a hand nebulizer.

\subsubsection{In Field Trials}

The evaluation of field performance of fungicides was carried out on experimental orchard with randomized complete block design with four replications (cv Imperatore Dallago, 8 years old in 2001). Treatments were arranged in a spray dispersion with a hand gun, considering 1000 litres/ha. AP fungicides were applied alone during the whole period of highest infective risk, starting after bud break and ending 2-3 weeks after the completion of bloom. AP fungicides were applied every 7 - 8 days. The doses were the same indicated in vivo tests (2.2.3).

Trifloxystrobin was employed in the same experimental orchard, and applied alone with a schedule of 9 - 10 days.

Apple scab incidence on leaves was performed by examining, in different vegetative moments, 150 leaves per each of the three replications for every fungicide.

\subsubsection{Fungicides}

The fungicides pyrimethanil and cyprodinil were applied as commercial products at label field doses (the same employed in vivo tests). Trifloxystrobin (Flint as commercial name, Bayer) was utilized with the dose of $0.15 \mathrm{~g} / \mathrm{L}$ ( $50 \%$ a.m.).

\section{Results}

\subsection{In Vitro Tests}

The in vitro results ( $\mathrm{mm}$ colonies and relative reductions) on pyrimethanil and cyprodinil are reported in Table 1, while in Figure 1 and Figure 2, the histograms show that isolates sensitivities $\left(\mathrm{EC}_{50}\right.$ values $)$ of pyrimethanil and cyprodinil are arbitrarily divided into 6 classes: $0.03-0.1,>0.1-0.3,>0.3-1,>1$ $-3,>3-10$ and $>10-30 \mathrm{mg} / \mathrm{L}$. 
Table 1. Results of in vitro tests on sensitivity to pyrimethanil and cyprodinil of monoconidial isolates from $V$. inaequalis populations with different origin and scab management.

\begin{tabular}{|c|c|c|c|c|c|c|c|c|}
\hline \multirow{2}{*}{$\begin{array}{l}\text { Origin of tested } \\
\text { populations }\end{array}$} & \multirow{2}{*}{$\begin{array}{l}\mathrm{N}^{\circ} \text { population } \\
\text { and year }\end{array}$} & \multirow{2}{*}{$\begin{array}{c}\mathrm{N}^{\circ} \\
\text { tested } \\
\text { isolates }\end{array}$} & \multicolumn{3}{|c|}{$\begin{array}{l}\text { Sensitivity to pyrimethanil } \\
\mathrm{EC}_{50}(\mathrm{mg} \text { a.i. } / \mathrm{L})\end{array}$} & \multicolumn{3}{|c|}{$\begin{array}{l}\text { Sensitivity to cyprodinil } \\
\mathrm{EC}_{50}(\mathrm{mg} \text { a.i./L) }\end{array}$} \\
\hline & & & mean & $\min$ & $\max$ & mean & $\min$ & $\max$ \\
\hline $\begin{array}{l}\text { Untreated trees in } \\
\text { uncultivated areas } \\
\text { (wild-types) }\end{array}$ & $12-2002$ & 20 & 0.64 & 0.034 & 1.60 & 0.034 & 0.003 & 0.19 \\
\hline $\begin{array}{l}\text { Commercial } \\
\text { orchard with good } \\
\text { control by Aps } \\
\text { (well-controlled) }\end{array}$ & $98-2004$ & 20 & 1.25 & 0.030 & 3.92 & 0.740 & 0.440 & 2.64 \\
\hline $\begin{array}{l}\text { Experimental } \\
\text { orchard with poor } \\
\text { control by } \\
\text { pyrimethanil }\end{array}$ & $103-2004$ & 39 & 3.54 & 0.230 & 18.30 & & & \\
\hline $\begin{array}{l}\text { Experimental } \\
\text { orchard with poor } \\
\text { control by } \\
\text { cyprodinil }\end{array}$ & $139-2005$ & 30 & & & & 1.680 & 0.320 & 7.41 \\
\hline
\end{tabular}

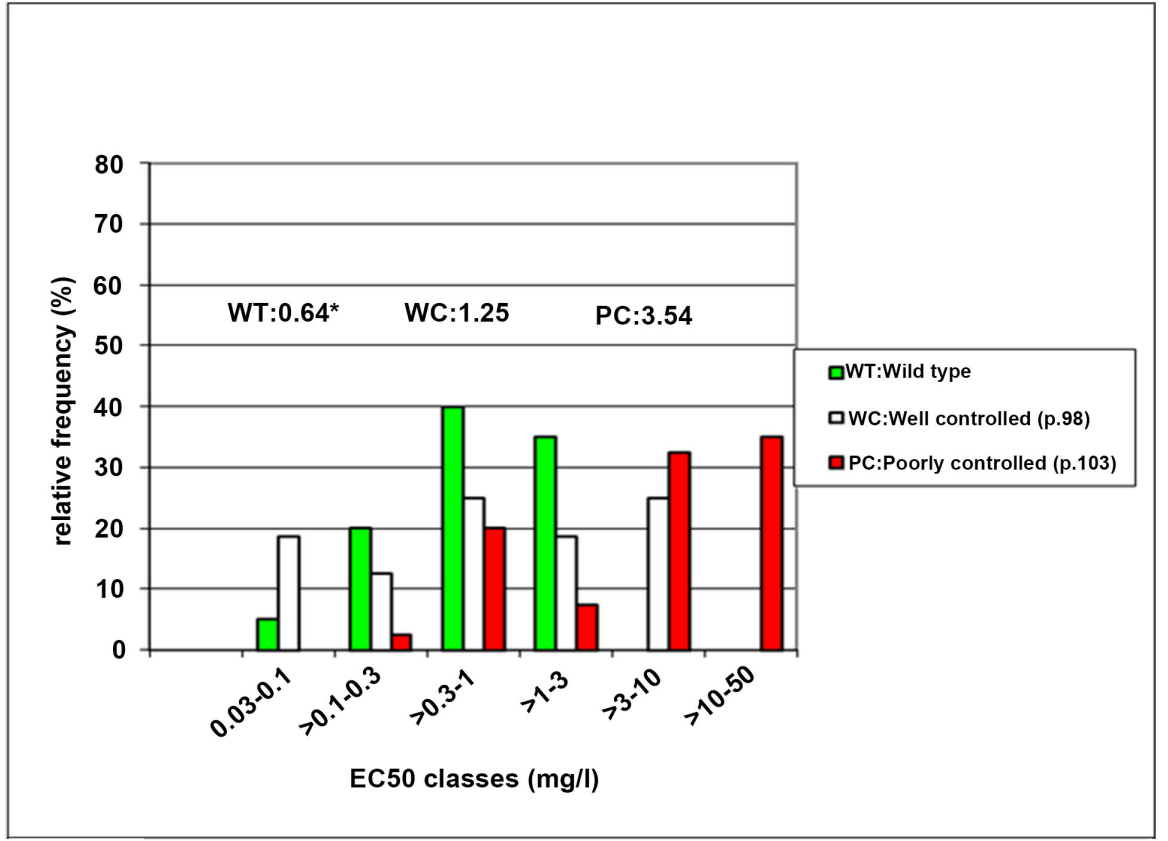

Fiure 1. Distribution in classes of sensitivity to pyrimethanil by monoconidial isolates belonging to the different types of $V$. inaequalis populations. ${ }^{*}$ mean $\mathrm{EC}_{50}$ value.

Concerning pyrimethanil, Figure 1 shows that the wild type isolates are distributed mostly in the first four classes $>0.03-0.1,>0.1-0.3,>0.3-1$ and $>1-3$ (respectively 5\%, 20\%, 40\% and 35\%), while isolates from well controlled population presented, respectively, a frequency of $18.7 \%, 12.5 \%, 25$ and $18.7 \%$. The highest difference between two types of isolates is in the following lower class (>3 - $10 \mathrm{mg} / \mathrm{l}$ ), where wild types have a frequency of $0 \%$, while the well controlled ones of $25 \%$. 


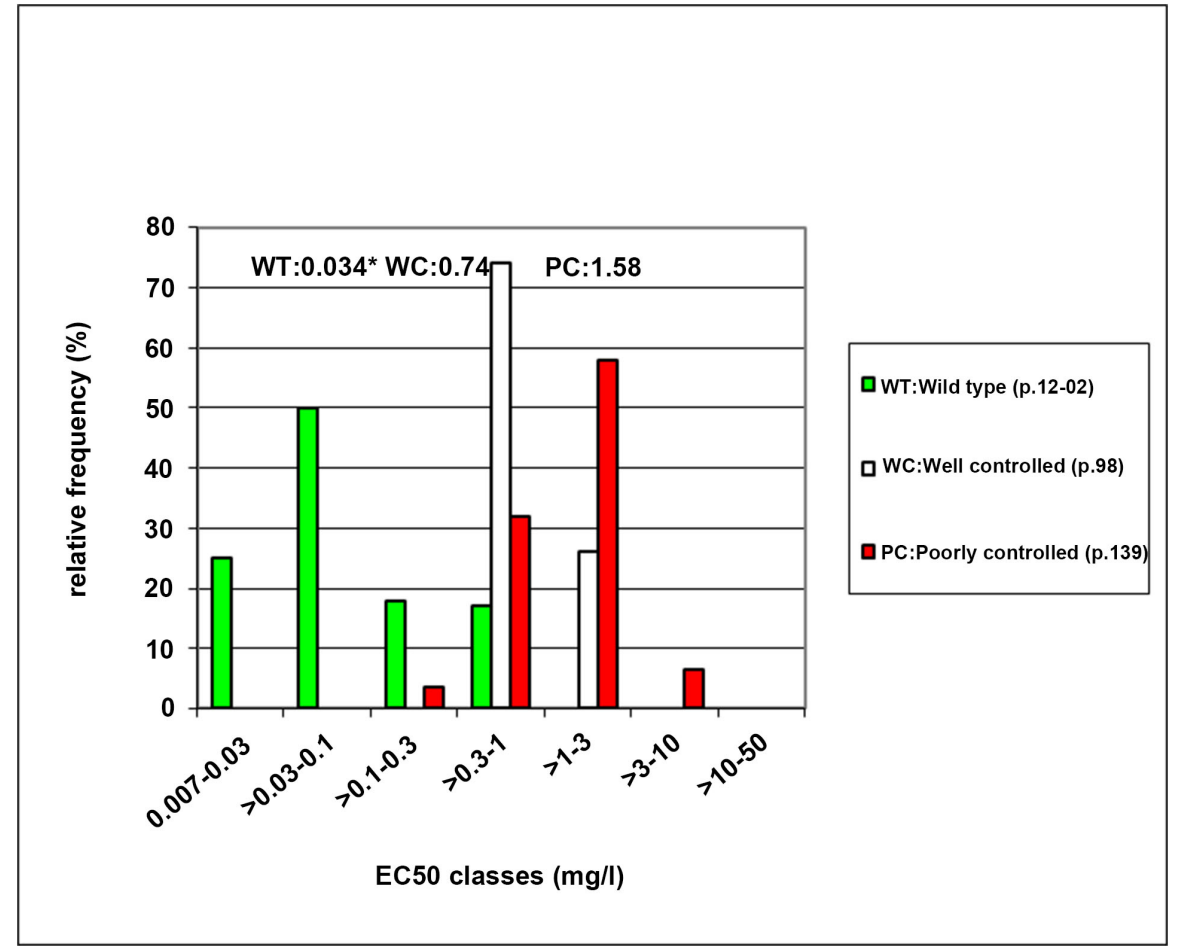

Figure 2. Distribution in classes of sensitivity to cyprodinil by monoconidial isolates belonging to the different types of $V$. inaequalis populations. ${ }^{*}$ mean $\mathrm{EC}_{50}$ value.

The isolates of poorly controlled population, show a slightly higher frequency in last class $>3-10 \mathrm{mg} / \mathrm{L}$ (32.5\%) with respect to $25 \%$ of well controlled ones, but it is the only presenting isolate $(35 \%)$ in the following class with sensitivity 3-fold lower (>10 to $30 \mathrm{mg} / \mathrm{L}$ ).

Comparing the mean sensitivities of these isolates, the wild-type ones present a mean $\mathrm{EC}_{50}$ of $0.64 \mathrm{mg} / \mathrm{L}$, which is 1.9 -fold lower than that of the well-controlled ones $\left(\mathrm{EC}_{50}: 1.25 \mathrm{mg} / \mathrm{L}\right)$. The mean $\mathrm{EC}_{50}$ of isolates from populations poorly controlled by pyrimethanil shows a value of $3.54 \mathrm{mg} / \mathrm{L}$ and it is, in turn, about 3-fold lower than that of the well-controlled populations and 5.5-fold lower respect mean $\mathrm{EC}_{50}$ value of wild types.

As regards cyprodinil (Figure 2), the wild type isolates are present from class $>0.007-0.03 \mathrm{mg} / \mathrm{L}$ to the immediately higher $>0.3-1 \mathrm{mg} / \mathrm{L}$ class, with a frequency of $24 \%$, while it is $70 \%$ the frequency of isolates of the well controlled types. These ones are present also in the next lower sensitivity class: $1-3 \mathrm{mg} / \mathrm{L}$ (a 3 -fold reduced sensitivity respect previous) with a frequency of $24 \%$, while wild-types are not present.

On the contrary, in this late class $(1-3 \mathrm{mg} / \mathrm{l})$ isolates poorly controlled by cyprodinil are present with a double higher percentage (58\%) respect well controlled. Moreover the poorly controlled ones are the only that show isolates (6.5\%) in the following less sensitivity class $(3-10 \mathrm{mg} / \mathrm{l})$.

Considering the mean $\mathrm{EC}_{50}$ values of all isolates amended with cyprodinil, the wild type ones show a value of $0.034 \mathrm{mg} / \mathrm{l}$, while for the well-controlled populations the main value is $0.74 \mathrm{mg} / \mathrm{l}$ (21.4-fold lower than wild-type ones) and mean 
$\mathrm{EC}_{50}$ value of poorly controlled ones is 1.58 (46.4-fold higher respect wild-types and 2.13-fold higher respect well-controlled ones).

\subsection{In Vivo Tests}

All sampled populations were assayed on apple seedlings with repeated preventive and curative applications. The tests showed a rather large variability of activity by the two APs, both with preventive or curative applications. The data are therefore presented as min. and max. values of relative efficacy (\%) assessed in realized trials on each population, as Table 2 shows.

The 1-day and 3-day preventive applications of pyrimethanil or cyprodinil showed a similar and very good activity on wild type populations, while on the well and poorly controlled ones, a a wider range of activity, also lower, was observed.

The well controlled showed the max relative efficiency (100\%) for pyrimethanil and cyprodinil, while the min were respectively 44.4 and 53.3, with treatments 3 days before inoculation. The poorly controlled populations evidenced values from 71.1 to 88.5 for max activity, while the lowest was from $55 \%$ to $50 \%$ for pyrimethanil and cyprodinil.

Curative applications ( 2 days) showed a high performance for both fungicides on wild type populations (between 80 and 100 as relative efficiency \%), while on the other ones a much wider range and lower values of activity were observed. In particular, on the populations from well-protected orchards (with AP fungicides), the max activity values were close to ones of the wild-type ones (between $80 \%$ and $90 \%$ ), while the lowest activity decreased to about $20 \%$.

The populations sampled in the experimental Centre and for the first time poorly controlled by pyrimethanil in 2004 and by cyprodinil in 2005 presented (Table 3 ) a low curative activity with 0 value (\% efficacy), as minimum while the maximum values were relatively high (about $80 \%$ for pyrimethanil and almost $60 \%$ for cyprodinil).

Also in 2006 and 2007, pyrimethanil and cyprodinil were applied with the same intensive criteria in the experimental orchard, and consequently the in vivo curative tests were repeated. Table 2 reassumes results as min and max curative activity from 2004 to 2007 of pyrimethanil and cyprodinil. In the repeated tests the lowest activity observed (as relative efficiency \%) ranged from 17.5 to 0 for pyrimethanil, while it was always 0 for cyprodinil. The highest activity ranged from 79 to 100 for pyrimethanil and from 40 to 78 for cyprodinil.

\subsection{In Field Trials}

The results in field trials presented in Table 4 show that the two AP fungicides sprayed at intervals of 7 - 8 days permitted very good control of apple scab (also in the severe epidemiological conditions of the experimental orchard) until 2003, while in 2004 for pyrimethanil and in 2005 for cyprodinil, a decrease of field activity was detected. The relative efficiency (\%) of pyrimethanil ranged from 53.3 
Table 2. In vivo activity of pyrimethanil and cyprodinil with preventive (1 - 3 days) or curative (2 days) applications on different types and origin of $V$. inaequalis populations.

\begin{tabular}{|c|c|c|c|c|c|c|c|c|c|c|c|c|c|c|}
\hline \multirow{3}{*}{ Origin and type } & \multirow{3}{*}{$\mathrm{n}^{\circ}$} & \multirow{3}{*}{$\begin{array}{l}\text { AP fungicide } \\
\text { applied and } \\
\text { (year of } \\
\text { collection) }\end{array}$} & \multicolumn{6}{|c|}{ Relative efficacy (\%) of pyrimethanil } & \multicolumn{6}{|c|}{ Relative efficacy (\%) of cyprodinil } \\
\hline & & & \multicolumn{4}{|c|}{ Preventive } & \multicolumn{2}{|c|}{$\begin{array}{l}\text { Curative } \\
2 \text { days }\end{array}$} & \multicolumn{4}{|c|}{ Preventive } & \multicolumn{2}{|c|}{$\begin{array}{l}\text { Curative } \\
2 \text { days }\end{array}$} \\
\hline & & & $\min$ & $\max$ & $\min$ & $\max$ & $\min$ & $\max$ & $\min$ & $\max$ & $\min$ & $\max$ & $\min$ & $\max$ \\
\hline $\begin{array}{l}\text { Untreated apple } \\
\text { trees in uncultivated } \\
\text { areas (wild-types) }\end{array}$ & $12-02$ & none (2002) & 100 & 100 & 100 & 100 & 75.0 & 100 & 100 & 100 & 100 & 100 & 71.4 & 100 \\
\hline $\begin{array}{c}\text { Commercial } \\
\text { orchards with good } \\
\text { control by } \\
\text { anilinopyrimidines }\end{array}$ & $\begin{array}{c}96,97,98, \\
99\end{array}$ & $\begin{array}{l}\text { pyrimethanil/ } \\
\text { cyprodinil } \\
(2004)\end{array}$ & 44.4 & 92.3 & 55.6 & 100 & 20.0 & 86.0 & 53.3 & 100 & 53.7 & 100 & 16.0 & 78.3 \\
\hline Experimental plots & 103 & $\begin{array}{c}\text { pyrimethanil } \\
\text { (2004) }\end{array}$ & 65.0 & 71.3 & 55.6 & 71.3 & 0.0 & 79.0 & & & & & & \\
\hline anilinopyrimidines & 139 & $\begin{array}{c}\text { cyprodinil } \\
(2005)\end{array}$ & & & & & & & 58.4 & 77.0 & 50.0 & 88.5 & 0.0 & 57.7 \\
\hline
\end{tabular}

Table 3. Results of in vivo tests in glasshouse on $V$. inaequalis populations treated intensively from 2004 to 2007 in experimental Centre and poorly controlled by pyrimethanil and cyprodinil.

\begin{tabular}{ccccc}
\hline & \multicolumn{3}{c}{ In vivo tests: max and min: relative efficacy (\%) observed in repeated } \\
curative tests in glasshouse
\end{tabular}

to 78.9 (from 2004 to 2006), while cyprodinil presented $81.0 \%$ in 2005 and $56.7 \%$ in 2006.

The fungicide of another chemical group, trifloxystrobin, showed very good activity with treatments every 9 - 10 days until 2001, while from 2003 to 2007, a severe decrease of activity was observed, with the field relative efficiency (\%) from a maximum of 34.0 to a minimum of 7.3 .

\section{Discussion and Conclusions}

I discuss the in vitro, in vivo and in field results about the sensitivity of $V$. inaequalis to APs (pyrimethanil and cyprodinil).

With reference to the monoconidial isolates in vitro tests, we observed very low values of "Resistance Factors" (RF) from sensitive to resistant populations (about 3-fold in our tests, 6-fold in Koller studies [11], from 3 to 30-fold from Kung [14]. 
Table 4. Field evolution of apple scab protection by AP fungicides with intensive and exclusive employ in an experimental Centre, compared with a strobilurin fungicide applied in the same way (trifloxystrobin).

\begin{tabular}{|c|c|c|c|c|c|c|c|c|}
\hline \multirow{3}{*}{ Fungicides } & \multirow{3}{*}{$\begin{array}{l}\text { Rate } \\
(\mathrm{g} \\
\text { a.i./l) }\end{array}$} & \multirow{3}{*}{$\begin{array}{c}\text { Treatments } \\
\text { schedule } \\
(\text { days })^{\mathbf{v}}\end{array}$} & \multicolumn{6}{|c|}{ Leaf scab severity $\%^{\mathrm{w}}$ and relative efficacy $\%^{\mathrm{y}}$} \\
\hline & & & 2001 & 2003 & 2004 & 2005 & 2006 & 2007 \\
\hline & & & 14.06 & 01.07 & 08.06 & 30.05 & 06.06 & 21.06 \\
\hline \multirow{2}{*}{ Pyrimethanil } & \multirow{2}{*}{0.30} & \multirow{2}{*}{$7-8$} & & $0.3 c^{w}$ & $22.5 \mathrm{~b}^{\mathrm{w}}$ & $10.0 \mathrm{c}^{\mathbf{w}}$ & $25.9 \mathrm{bc}^{\mathrm{w}}$ & $12.6^{\mathrm{w}}$ \\
\hline & & & & $(96.4)^{y}$ & $(53.6)^{\mathrm{y}}$ & $(78.9)^{y}$ & $(53.3)^{\mathrm{y}}$ & $(66.5)^{y}$ \\
\hline Cyprodinil & 0.25 & $7-8$ & & $\begin{array}{l}0.56 \mathrm{c} \\
(93.3)\end{array}$ & 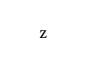 & $\begin{array}{l}9.0 \mathrm{~cd} \\
(81.0)\end{array}$ & $\begin{array}{c}24.0 \mathrm{~cd} \\
(56.0)\end{array}$ & $\begin{array}{c}9.3 \\
(75.1)\end{array}$ \\
\hline Trifloxystrobin & 0.075 & $8-10$ & $\begin{array}{l}5.4 \mathrm{ab} \\
(98.6)\end{array}$ & $\begin{array}{c}6.2 \mathrm{~b} \\
(26.2)\end{array}$ & $\begin{array}{l}43.2 \mathrm{a} \\
(10.9)\end{array}$ & $\begin{array}{l}37.3 \mathrm{~b} \\
(21.3)\end{array}$ & $\begin{array}{c}51.4 \mathrm{a} \\
(7.3)\end{array}$ & $\begin{array}{c}24.8 \\
(34.0)\end{array}$ \\
\hline Untreated & & & $73.8 \mathrm{a}$ & $8.4 \mathrm{a}$ & $48.5 \mathrm{a}$ & $47.4 \mathrm{a}$ & $55.5 \mathrm{a}$ & 37.6 \\
\hline
\end{tabular}

"Fungicides were applied from the phase of "mouse ears" to "fruit set". "Scab severity as mean percentage of infected area on leaves from four replicates per treatment. 150 leaves counted in each replicate. Means not followed by a common letter are significantly different $(\mathrm{P} \leq 0.05)$ according to Duncan's test. ${ }^{\mathrm{y}}$ Relative efficiency (\%) of fungicide. ${ }^{\mathrm{T}}$ The scab control program was not carried out only with cyprodinil, but with other products.

In $V$. inaequalis, the RF values appear different from that of Botrytis cinerea where resistant spores showed a wider RF range with very high values (RF from 2 - 3 to 100 and 1000). The cause of the absence of $V$. inaequalis strains with a high reduction of in vitro sensitivity does not seem to be related to agars too rich in carbohydrates, as supposed at the beginning of sensitivity assays [18]. Indeed the researchers subsequently conducted by Koller [11] with Czapeck and PDA, with Hammer agar [14], and my researchers (with malt extract and "Agar Grade A") found the same results with clearly inferior and similar quantities of sugars.

I do not presume that resistant monoconidial isolates of $V$. inaequalis, show a low difference of growth respect sensible ones because $V$. inaequalis monoconidia have normally a low increase. Indeed in others situations, as with strobilurins, the difference in development between sensible and resistant monoconidial colonies appeared very strong [19].

The in vivo tests examined the three types of field $V$. inaequalis populations (wild types, well or poorly controlled) by pyrimethanil or cyprodinil, applying the same fungicides on these populations in a curative or preventive way.

These researches evidenced that curative tests, much more than preventive ones, permit to evidence differences between the sensitivity of the different types of populations.

Indeed, in curative applications the wild types presented an activity always higher than $75 \%$, while the well controlled ones evidenced a wide range: the higher relative efficiencies are similar to those of wild-types, while the lowest reach the $20 \%$ of activity. The poorly controlled ones showed likewise a wide range, but more shifted towards lower values, from $79 \%$ to $0 \%$, so inferior to the lowest value (20\%) of well controlled.

This borderline value (20\%) was used in surveys to discriminate the poorly controlled populations from the others. However, the wide range of values showed by populations of the different types, requires that tests are repeated, at 
least two or three times, on each subpopulation [20].

These data show that that $V$. inaequalis populations can more easily show a reduction of sensitivity in curative applications in comparison with preventive ones. Must be pointed out that the same behaviour was observed in DMIs, with researches on difenoconazole, the most used DMI [21].

These results of curative assays on APs have no possibility of comparison because this type of application has ever been experimented and compared with preventive ones. There is only a study by Schnabel \& Parisi [22] that in one strain of Venturia inaequalis, showed a very low sensitivity on AP fungicides in vitro tests, but in vivo (with preventive and curative applications), the sensitivity appeared normal. No successive researches were carried out to deep and explain these differences.

On the contrary, bibliography is richer about in vivo tests on populations with preventive applications, realized one day before inoculation and with different concentrations [10] [13] [14]. The results show that the main $\mathrm{EC}_{50}$ values of sensitive populations to pyrimethanil and cyprodinil (baseline or treated without problems) ranged between 3 and $100 \mathrm{mg} / \mathrm{L}$, and the resistant ones were positioned in the range from 100 to $>300 \mathrm{mg} / \mathrm{L}$ by Kung [14], while Dux [13], from $300 \mathrm{mg} / \mathrm{L}$. Thereafter also with this methodology, it is often difficult to clearly discriminate sensible from resistant populations.

It is a matter if a methodology based on different concentrations in preventive applications is better than that with curative treatments and field doses. I retain that the last methodology seems more near to the reality of fungicides' application.

Moreover, in field trials (on experimental orchard), the applications of pyrimethanil and cyprodinil, with intensive schedules and reiterated in years, caused a repeated, but moderated reduction of activity, aligning with the results occurred in vitro and in vivo tests, where the differences were more visible related to curative applications. Clearly different is the situation of strobilurins (results of trifloxystrobin are reported) that showed, in the same experimental orchard and in similar management, very high control failures, corresponding to heavy sensitivity reductions in vitro tests [20].

In conclusion, the in vitro, in vivo and in field tests show the possibility of reduced sensitivity of Venturia inaequalis to AP fungicides, with possibility of unsatisfying control. Some conditions seem to favourate this problem: a high number of treatments, APs used alone, with an employ, especially curative. The reductions of sensitivity and activity observed in each of the three types of tests were, always moderate, and this should be a sign of a particular mechanism of resistance.

Our data referred let to suppose a polygenic resistance mechanism on AP fungicides also for the limited number of cases of resistance assessed by us in Italy by Fiaccadori [20] and other Authors in the last 30 years. The researches by Dux [13] and Koller [11] come to the same conclusions. However the same Dux admits that there is no a genetic proof that lets to postulate this mechanism of action. 
Must be pointed out that previous genetic studies by Hilber \& Hilber-Bodmer [22] produce data that do not agree substantially with this hypothesis because support that the resistance mechanism of fungi to AP fungicides is monogenic, or with a major gene.

The more recent research, by Fritz [23] presented a partial explanation of a polygenic mechanism, and so the question is not solved.

\section{Acknowledgements}

I wish to thank Emilia-Romagna Region for economic support and help by technical staff of Integrated Pest Management (IPM); Prof. A. Brunelli for field data, G. Toschi, A. Finestrelli and E. Cicognani for technical support in laboratory and glasshouse tests, M. Collina for logistic help.

\section{Conflicts of Interest}

The author declares no conflicts of interest regarding the publication of this paper.

\section{References}

[1] Maeno S., Miura I., Masuda, K. and Nagata, T. (1990) Mepanypirim (KIF-3535), a New Pyrimidine Fungicide. Brighton Crop Protection Conference-Pests and Diseases, 2, 415-422.

[2] Neuman, G.L. and Winther, E.H. (1992) Pyrimethanil: A New Fungicide. Brighton Crop Protection Conference-Pests and Diseases, 1, 395-402.

[3] Heye, U.J., Speich, J., Siegle, R., Wohlauser, A. and Hubele, A. (1994) CGA 219417-A Novel Broad-Spectrum Fungicide. Brighton Crop Protection Conference-Pests and Diseases, 2, 501-508.

[4] Creemers, P., Brugmans, W. and Vanmechelen, A. (1995) The Anilino-Pyrimidines, an Interesting New Fungicide Family to Control Diseases in Fruit Culture. Mededelingen-Faculteit Landbouwkundige en Toegepaste Biologische Wetenschappen. Universiteit Gent (Belgium), 60, 353-360.

[5] Moyano, C., Gomez, V. and Melgarejo, P. (2004) Resistance to Pyrimethanil and other Fungicides in Botrytis cinerea Populations Collected on Vegetable Crops in Spain. Journal of Phytopathology, 152, 484-490.

https://doi.org/10.1111/j.1439-0434.2004.00880.x

[6] Hilber, U.W. and Hilber-Bodmer, M. (1998) Genetic Basis and Monitoring of Botryotinia fuckeliana to Anilinopyrimidines. Plant Disease, 82, 496-500. https://doi.org/10.1094/PDIS.1998.82.5.496

[7] Myresiotis, C.K., Karaoglanidis, G.S. and Tzavella-Klonari, K. (2007) Resistance of Botrytis cinera Isolates from Vegetable Crops to Anilinipyrimidine, Phenylpirrole, Hydroxyanilide, Benzimidazole, and Dicarboximide Fungicides. Plant Disease, 91, 407-413. https://doi.org/10.1094/PDIS-91-4-0407

[8] Latorre, B.A., Spadaro, I. and Rioja, M.E. (2002) Occurrence of Resistant Strains of Botrytis cinerea to Anilinopyrimidine Fungicides in Table Grapes in Chile. Crop Protection, 21, 957-961. https://doi.org/10.1016/S0261-2194(02)00074-1

[9] Schnabel, G. and Parisi, L. (1997) Sensitivity of Venturia inaequalis to Five DMI Fungicide, Including the New Triazole Fluquinconazole, and to Pyrimethanil. 
Zeischrift fur Pflanzenkrankheiten und Pflanzeschutzl Journal of Plant Diseases and Protection, 104, 36-46.

[10] Kunz S., Lutz, Bu., Deising, H. and Mendgen, K. (1998) Assessment of Sensitivities to Anilinopyrimidine- and Strobilurin Fungicides in Populations of the Apple Scab Fungus Venturia inaequalis. Journal of Phytopathology, 146, 231-238. https://doi.org/10.1111/j.1439-0434.1998.tb04684.x

[11] Koller, W., Wilcox, W.F. and Parker, D.M. (2005) Sensitivity of Venturia inaequalis Populations to Anilinipyrimidines and Their Contribution to Scab Management in New York. Plant Disease, 89, 357-365. https://doi.org/10.1094/PD-89-0357

[12] Masner, P., Muster, P. and Schmid, J. (1994) Possible Methionine Biosynthesis Inhibition by Pyrimidinamine Fungicides. Pesticide Science, 42, 163-166.

https://doi.org/10.1002/ps.2780420304

[13] Dux, H., Sierotzki, H., Meier-Runge, F. and Gisi, U. (2005) Sensitivity of Venturia inaequalis Populations to Anilinopyrimidines, DMI and QoI Fungicides. Modern Fungicides and Antifungal Compounds IV 2005, 45-54.

[14] Kung, R., Chin, K.M. and Gisi, U. (1998) Sensitivity of Venturia inaequalis to Cyprodinil. Modern Fungicides and Antifungal Compounds II, 313-322.

[15] Micoud, A. and Remuson, F. (2006) La tavelure du pommier: Comment gérer les resistences. Phytoma-La défense des végétaux, 590, 20-23.

[16] Fiaccadori, R., Cicognani, E., Collina, M. and Brunelli, A. (2007) Study on the Sensitivity of Venturia inaequalis to Anilinopyrimidine Fungicides in Italy. Proceedings of 59th Symposium on Crop Protection 2006, Ghent (B) 10.05.2007 pubbl. on "Communications in Agricoltural and Applied Biology Sciences", Ghent University, 72, 997-1001.

[17] Brent, K.J. and Hollomon, D.W. (1998) Fungicide Resistance: The Assessment of Risk. FRAC Monograph No.2, GCPF, Brussels.

[18] Hilber, U.W. and Schuepp, H. (1996) A Reliable Method for Testing the Sensitivity of Botriotinia fuckeliana to Anilinopyrimidines in Vitro. Pesticide Science, 47, 241-247. https://doi.org/10.1002/(SICI)1096-9063(199607)47:3<241::AID-PS410>3.0.CO;2-6

[19] Fiaccadori, R., Cicognani, E., Alberoni, G., Collina, M. and Brunelli, A. (2011) Sensitivity to Strobilurin Fungicides of Italian Venturia inaequalis Populations with Different Origin and Scab Control. Pest Management Science, 67, 535-540. https://doi.org/10.1002/ps.2090

[20] Fiaccadori, R., Collina, M. and Brunelli, A. (2013) Reduced Sensitivity of Venturia inaequalis to Strobilurins and Anilinopyrimidines in Italy. Integrated Protection of Fruit Crops IOBC-WPRS Bulletin, 91, 345-350.

[21] Fiaccadori, R. (2017) Researches on Methodologies to Verify Reduced Sensitivities of Venturia inaequalis in Field to Difenoconazole and First Indications of a Survey in Italy. American Journal of Plant Sciences, 8, 2056-2068.

https://doi.org/10.4236/ajps.2017.89138

[22] Schnabel, G. and Parisi, L. (1998) Testing New Fungicides to Reduce Apple Scab. Acta Horticulture, ISHS, 466, 83-87.

[23] Fritz, R., Lanen, C., Chapeland, F. and Leroux, P. (2003) Effect of the Anilinopyrimidine Fungicide Pyrimethanil on the Cystathionine $\beta$-Liase of Botrytis cinerea. Pesticide Biochemistry and Physiology, 77, 54-65. https://doi.org/10.1016/S0048-3575(03)00094-4 